\title{
Glanz und Elend der Wellnesspioniere
}

Erhard Taverna

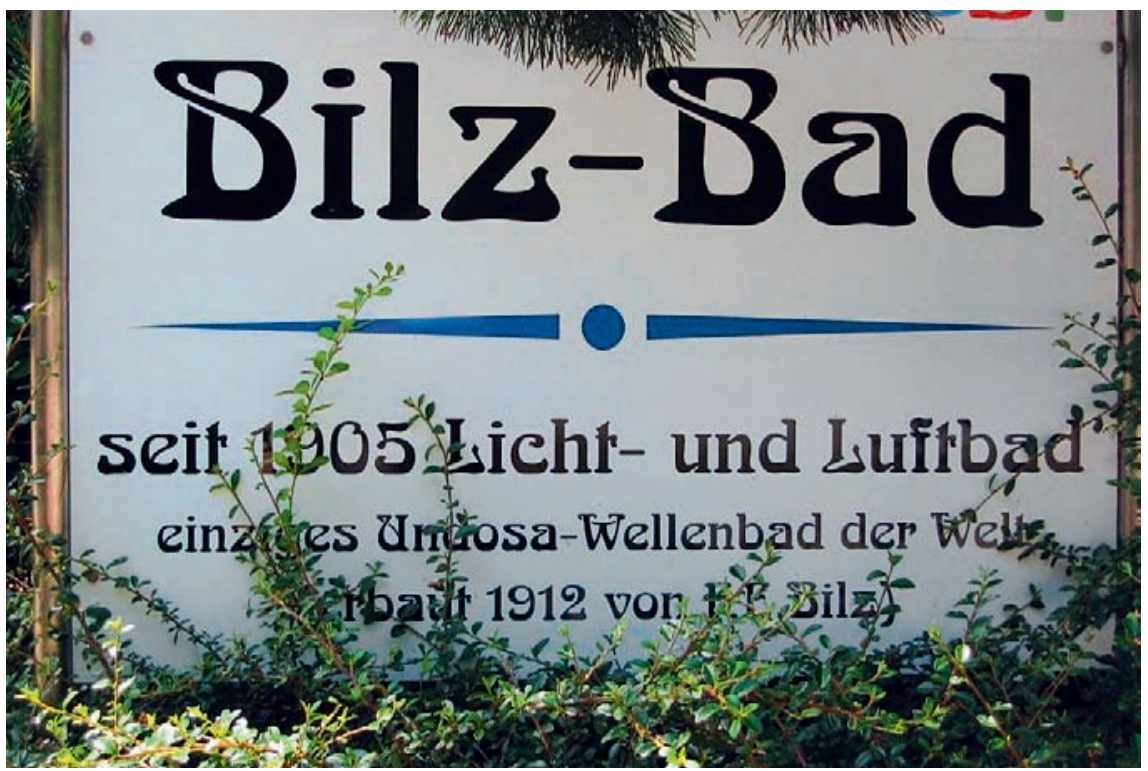

tum. Die Schrift fand, mit Abstrichen am Sozialprogramm, einen riesigen Absatz und wurde, mehrmals überarbeitet aufgelegt, in 12 Sprachen übersetzt, bis 1938 rund 3,5 Millionen Mal verkauft. Das «Bilz-Buch» ist der klassische Bestseller aller Gesundheitsratgeber, dem auch das Konkurrenzprodukt und teilweise Plagiat seines Privatsekretärs Moritz Platen wenig anhaben konnte. Bilz war auch ein äusserst innovativer Unternehmer, der seine Ideen mit einem illustrierten Familienblatt vertrieb, ein Sanatorium gründete und noch in hohem Alter auf neuste Entwicklungen wie den Film reagierte. Er war Teilhaber einer Filmgesellschaft, die auch zwei Filme nach Vorlagen seines Freundes Karl May drehte. Bilz erfand im Kampf gegen den verbreiteten Alkoholkonsum ein Fruchtgetränk aus Südfrüchten und einheimischem Obst, die «Bilz-Limetta» oder «BilzBrause», ab 1906 weltweit bis heute als «Sinalco» vermarktet. Mit dem Autorenerlös baute er in Oberlössnitz ein Sanatorium mit Kurhäusern, in dem auch mit modernen Formen der Elektrotherapie behandelt wurde. Als Direktoren wurden Naturkundler eingestellt, von denen Otto Wagner nach seinem Weggang das Sanatorium Oberwaid bei St. Gallen erwarb und betrieb. Weil in Sachsen nur naturwissenschaftlich ausgebildete Ärzte medizinische Institutionen leiten durften, arbeiteten Mediziner mit, darunter auch ein fanatischer Impfgegner, der einen der ersten Ärztevereine gegen das Impfen gründete. Nicht ganz unschuldig war der Ehrenrat der ärztlichen Standesorganisation, der alle Kollegen als Kurpfuscher verunglimpfte und ausgrenzte, die in naturkundlich geleiteten Sanatorien arbeiteten.

Auch Ärzte gehörten zu den Pionieren, etwa Dr. Paul Kadner als Verfechter der «Schrothkur» und anderer Diäten oder Dr. Heinrich Lahmann, der 1888 sein «Physiatrisches Sanatorium» für gehobene Preisklassen eröffnete. Er plädierte für Wasserkuren, Massagen und Diäten. Die von Koch vertretene Bakteriologie lehnte er ab und damit auch Impfungen, die er als nutzlos und schädlich beurteilte. Der Schweizer Ernährungsreformator Max Bircher-Benner (1867-1939) holte sich bei ihm Anregungen für seine neuen Rezepte. Stets von Schulmedizinern angefeindet, war Lahmann ein erfolgreicher Lehrer weiterer Ärzte. Der schwedische Chemiker und Mineralstofforscher Ragnar Berg entwickelte seine Ansichten weiter und begründete die Lehre von der 
«basenüberschüssigen Kost», auch «Säure-BasenTheorie» genannt, die von der Schulmedizin abgelehnt, bis heute in der alternativen Szene weitverbreitet ist.

Alles was in der Kunst und Politik Ruhm und Rang einnahm, fand sich in diesen Sanatorien ein, wie zahlreiche Gemälde und literarische Zeugnisse belegen. Barlach, Kokoschka, Kirchner, Wigman, Palucca, Adelige, Militär, Politik und Hochfinanz fanden hier ihren «Zauberberg».

Bereits 1925 stellten Sozialdemokraten des Dresdener Stadtrates den Antrag: «Das Kollegium wolle beschliessen in einer Krankenanstalt je eine besondere Abteilung für Naturheilweise und Homöopathie einzurichten.» Unter dem Hakenkreuz erfuhr die Naturheilkunde eine weitere gesundheitspolitische Aufwertung. Hitler war als Vegetarier an alternativen Heilmethoden interessiert, eine gesunde Lebensweise sollte zur Pflicht und Krankheit zur persönlichen Schuld werden. Erklärtes Ziel des Reichsärzteführers war ein Zusammenschluss der Naturheilkunde mit der universitären Medizin, wozu das Johannstädter Krankenhaus in Dresden, zum «Rudolf-Hess-Krankenhaus» umbenannt, eine für die Welt beispiellose Synthese einleiten sollte. Für die drei neuge- schaffenen «biologischen Abteilungen» wurden gemeinsame Chefarztstellen aus beiden Bereichen eingerichtet. Eine Fortbildungsschule unterrichtete Ärztinnen und Ärzte während dreier Wochen in der neuen Kombination. 1939 war die Grundsteinlegung für die «Rudolf-Hess-Akademie für Naturheilkunde», ein Experiment, das der Kriegsverlauf vorzeitig beendete.

Die Sanatorien wurden fast alle in Reservelazarette oder Quartiere für Armeestäbe umgewandelt. Der Schriftsteller Gerhart Hauptmann (1862-1946) war im letzten der verbliebenen Sanatorien ein Augenzeuge der totalen Zerstörung Dresdens. Diese Klinik wurde von den Russen übernommen, 1951 an die Nationale Volksarmee der DDR übergeben und ab 1991 von der Bundeswehr genutzt. Heute betreibt darin das neue Klinikmanagement eine onkologische Klinik.

Eduard Bilz hat die Plünderung seiner Klinik 1945 und den späteren Zerfall nicht mehr erleben müssen. An ihn erinnert eine Bronzebüste am Eingang der Badeanstalt. Der Rest ist Geschichte.

- Lienert M. Naturheilkundiges Dresden. Dresden: Elbhang-Kurier-Verlag; 2002. 160 Seiten. 